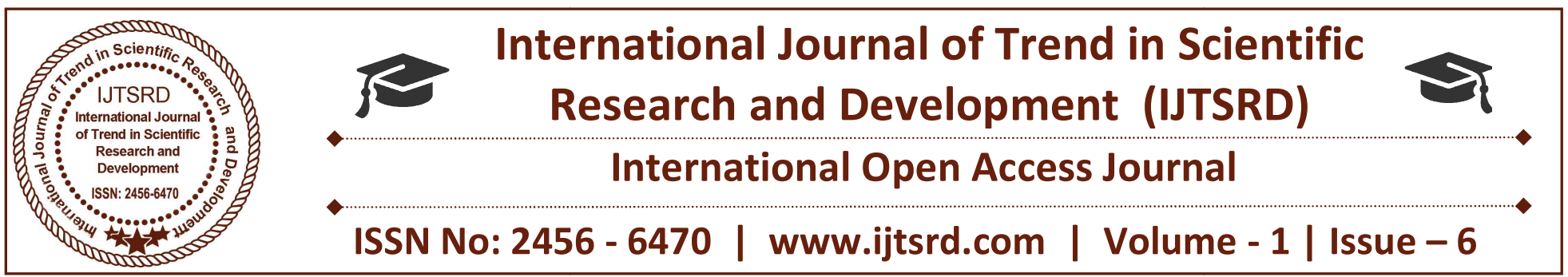

\title{
Automatic Bottle Filling System using PLC
}

Mrs Shweta Suryawanshi

Department of Electronics and Telecommunication, Pune University Dypiemr, Pune, India

\section{Mr. Mangesh Tandale}

Department of Electronics and Telecommunication, Pune University Dypiemr, Pune, India
Mr. Dhananjay Shelke

Department of Electronics and Telecommunication, Pune University Dypiemr, Pune, India

\section{Mr. Akshay Patil}

Department of Electronics and Telecommunication, Pune University Dypiemr, Pune, India

\section{ABSTRACT}

This paper presents the automatic water bottle filling system using plc and scada. Automation is the field which reduces the human efforts and labour requirement. One of the important applications of the automation is in the soft drinks and other beverage industries, where the particular liquid has to be filled continuously. The machines are specialist for filling water in any kind of bottle. This bottle filling mechanism is done using the various types of sensors. The filling operation is controlled using plc and scada. This whole process is done using the various components like solenoid valve, conveyor belt, sensors.

Keywords: plc, scada, photoelectric sensors, flow sensor, conveyor belt, solenoid valve, HMI

\section{INTRODUCTION}

Basically Automation is the thing which reduces the human work and increases the productivity. When the technology increases the productivity also increases. Automation is the one time investment which will help in economy and productivity. Most important application of automation is in soft drinks bottle filling. Our paper presents the water bottle filling using PLC and scada. Here we interface the PLC with scada by the RS232 cable so that scada will monitor the whole process of the automation. Our project having three sections includes the Sensing the bottle on the conveyor belt then dispensing the desired amount of liquid into the bottle by the solenoid valve which is below the tank of the liquid. Then it will move the bottle over the conveyor belt. Ladder logic is used to control the whole process. And the sensors are used to sense the bottles and the liquid dispense in the bottle. Filling is done by opening and closing of the solenoid valve.

\section{PROPOSED SYSTEM}

The block diagram of the system is as shown in the fig. Where the block diagram consist of the following main blocks as input module, signal conditioning, plc and scada, solenoid valve, output module. These all blocks are help to do the filling operation of the bottle. 


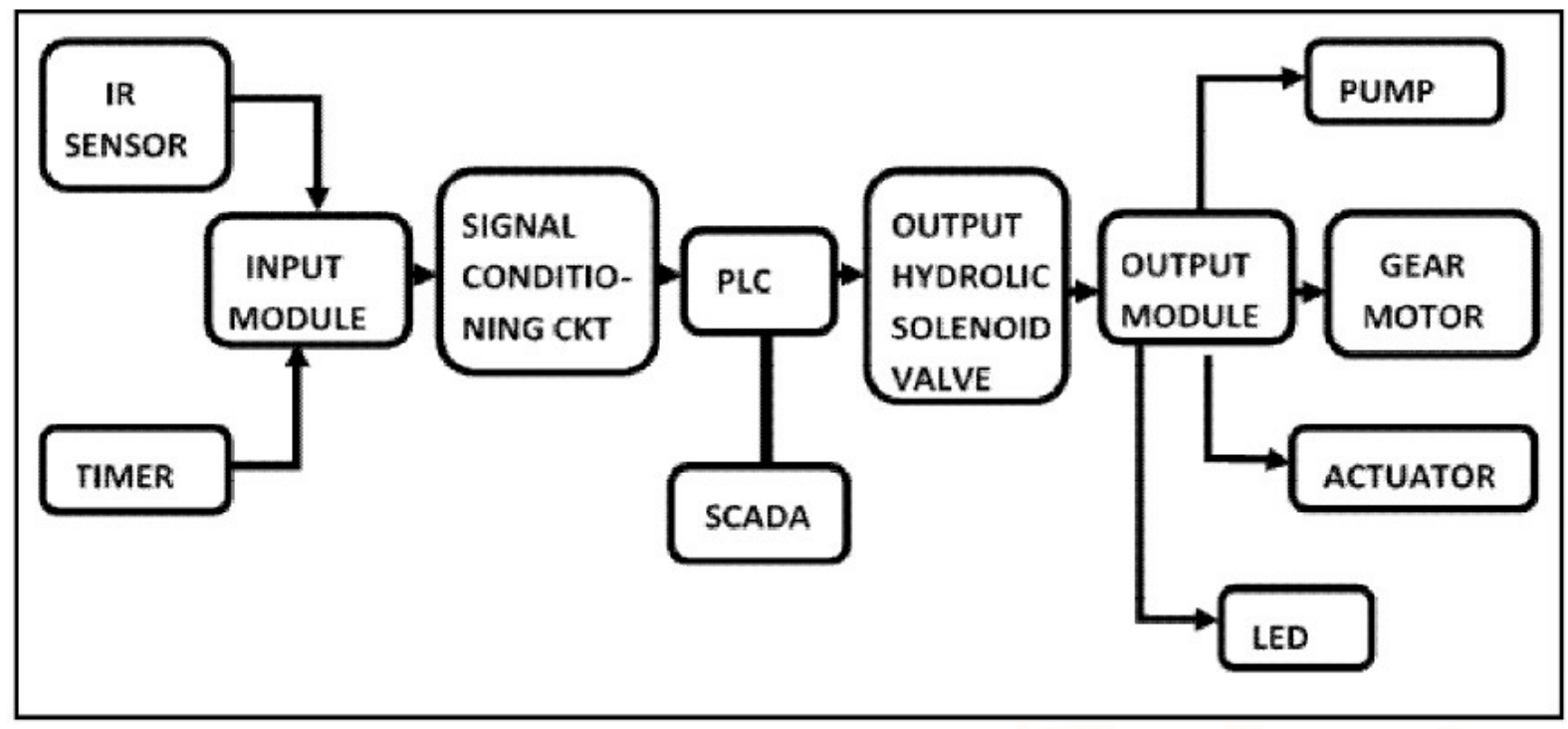

Fig 1: Block diagram of bottle filling

\section{Input Module:}

In the input of this module consist of the various types of sensors which are the IR sensors and level sensors. Which detect the presence of the bottle and the level of the amount of water is filled in the bottle.

\section{Signal Conditioning:}

The output we are getting from the sensors we cannot directly give to the plc because plc requires the input about $24 \mathrm{v}$. Hence signal conditioner increases the strength of the output of IR sensors. It amplifies the output of sensors.

\section{PLC and Scada:}

PLC help in the automation process, it will get the input from the sensors and gives the output to the valve and output module. Scada will monitor the whole system.

\section{Solenoid valve:}

It helps to fill the bottle by opening and closing the valve of the tanks when detection of the bottles takes place.

\section{Output Module:}

In the Ouput modules consist of Pump, motor, LED and Actuators. Output module gets the signal from PLC.

\section{HARDWARE PART:}

PLC: Here we used PLC (micrologix 1400) which is having 8 input and 4 relay output, scada interface with plc so both can control the whole process.plc work on ladder logic program.

Solenoid Valve: It helps to fill the bottle by opening and closing the valve of the tanks when detection of the bottles takes place.

Conveyor belt: Conveyor belt is long loop rubber or plastic, which is used for moving the strip of bottle.

\section{SOFTWARE PART:}

In Software Part we are going to discuss about the programs and logics used. In this part we have used ladder logic. Basically plc works on ladder programming which is easy to implement and less complexity.

\section{ADVANTAGES:}

1. Reduce the human efforts and physical work.

2. Replacing human work by technologies.

3. Economy improvement.

4. Perform the tasks which are beyond the human capabilities of size, weight, speed.

\section{DISADVANTAGES:}

1. Unemployment increases due to machine replacing human.

2. Development cost cannot predict.

3. Huge initial investment.

4. Positioning of solenoid valve is critical issue. 


\section{CONCLUSION:}

The system can perform the task of autonomous quality control system used in industrial production and most suitable for small scale industries. We develop a bottle filling system based on specification of dispensing liquid. We acquire the great knowledge about the automation.

\section{REFERENCES:}

1) "AUTOMATIC LIQUID FILLING TO BOTTLES OF DIFFERENTHEIGHT USING PROGRAMMABLE LOGIC CONTROLLER" MALLARADHYA H M, K $\mathrm{R}$ PRAKASH, International Journal of Mechanical and Production Engineering, ISSN: 2320-2092, Volume- 1, Issue- 4, Oct-2013

2) "Automatic Multivariate Liquid Filling System \& Conveyor Control Using PLC \& SCADA" , Dheeraj Pongallu, Prof. S. R. Suralkar , International Journal of Emerging Technology and Advanced Engineering (ISSN 2250-2459, ISO 9001:2008 Certified Journal, Volume 4, Issue 12, December 2014)

3) “ Energy Efficient Automized Botteling Plant Using Plc And Scada With Speed Variable Conveyor Assembly", Sagar P. Jain, Dr. Sanjay L. Haridas, IOSR Journal of Electronics and Communication Engineering (IOSR-JECE) eISSN: 2278-2834,p- ISSN: 2278-8735.Volume 9, Issue 1, Ver. II (Jan. 2014), PP 09-14
4) "Automation of Bottle Filling Plant with Industry 4.0" , Sagar T. Payghan1, Rani H. Deshmukh2, Puja P. Magar3,Vinod M. Manure4, International Journal of Advanced Research in Electrical ,Electronics and Instrumentation Engineering (An ISO 3297: 2007 Certified Organization)Vol. 5, Issue 3, March 2016

5) "Introduction to Programmable Logic Controllers" - Dunning Gray (1998), Delmar publishers, pp.421-428. 